\title{
DISCHARGE COEFFICIENT OF HIGH VISCOSITY LIQUIDS THROUGH NOZZLES
}

\author{
S. Essien ${ }^{\mathrm{a}, \mathrm{b}}$, A. Archibong-Eso ${ }^{\mathrm{a}, \mathrm{c}, *}$, L. Lao ${ }^{\mathrm{a}}$ \\ ${ }^{a}$ Oil and Gas Engineering Centre, School of Water, Energy \& Environment, Cranfield University, UK \\ ${ }^{a}$ Department of Agricultural and Food Engineering, University of Uyo, Nigeria \\ ${ }^{c}$ Department of Mechanical Engineering, Cross River University of Technology, Calabar, Nigeria. \\ *Corresponding Author: A. Archibong-Eso, archibong.eso@gmail.com
}

\begin{abstract}
Experimental investigation on discharge coefficient, $C_{d}$, for high viscosity fluid through nozzles was carried out. The viscosity of the fluid used for the test ranged from 350 to 1500 $\mathrm{mPa}$. The length-to-diameter ratio of the nozzle, $l / d$ and the ratio of nozzle diameter to pipe diameter ratios $\beta$ were used to investigate the influence of geometry on $C_{d}$. Results show a significant dependence of $\mathrm{C}_{\mathrm{d}}$ on $\mathrm{Re}, l / d$ and $\beta$ ratio. An empirical correlation on the discharge coefficient was developed based on the data from this study which was also compared with data from other published studies. This correlation, with an R-squared value of 0.9541, was valid for nozzle sizes $10-20 \mathrm{~mm}$ and for Re between 1 and 2000. $\mathrm{C}_{\mathrm{d}}$ values obtained from experimental data, and those from the empirical correlation were compared, and a mean standard deviation of 0.0231 was obtained.
\end{abstract}

Keywords: discharge coefficient; Reynolds number; length-to-diameter ratio; beta ratio; viscosity 


\section{Introduction}

Discharge coefficient is a ratio of the actual volume flow rate through a constriction to the theoretical or ideal volume flow rate of a fluid. It is a dimensionless number used to characterise the flow and pressure loss behaviour of nozzles and orifices in fluid systems (Neutrium, 2015) ranging from measurement of fluid flow through different types of differential pressure flow meters to mixing processes. Discharge coefficient was used in measuring the flow through a circular orifice, cut into thin-walled vertical riser pipe which served as a control structure for storm-water detention basins (Prohaska, 2008). It was also applied to pressurised hydraulic spargers used in a cooling tower or power generation (Werth et al., 2005). As a result of different head losses which occurs in the nozzles, $C_{d}$ is used to get the actual discharge from ideal or theoretical discharge (that is, flow rate based on assumptions which do not hold in practice (Eq. 1). This study focuses on the discharge coefficient of an orifice type nozzle.

$$
C_{d}=\frac{\text { Actual discharge, } Q_{\text {actual }}}{\text { Theoretical discharge, } Q_{\text {theoretical }}}
$$

The discharge coefficient is a function of the following factors: Reynolds number (Re) and geometry (that is, length-to-diameter ratio and diameter ratio) of the nozzle. Other geometrical factors are the shape of the pipe section where the nozzle is installed, and for orifice type nozzle, the upstream edge sharpness, i.e. the sharpness of the edges of the orifice significantly affects the discharge coefficient (Hobbs and Humphrey, 1990). While the influence of lengthto-diameter ratio is significantly dependent on the length of the orifice, the beta ratio increases as the small diameter get larger, assuming the larger diameter is fixed (Lichtarowicz et al., 1965). Reynolds number has a significant effect on discharge coefficient at low values (laminar regime), but this influence diminishes as it attains a higher value (turbulent regime) from Re $>10^{4}$ (Bohra, 2004). 
Numerous reports on studies regarding the influence of Reynolds number on discharge coefficient are particularly focused on low viscous fluids. Some previous works are presented in Table 1. In contrast, high viscous fluids are often encountered in industries as products or materials, for instance, honey, food concentrate etc., in the food industry, and heavy oils in the oil and gas industry. However, the research outputs on high viscous fluids are relatively limited. A review of the literature revealed that test fluids for most studies were air, diesel fuel, water and glycerol (for high viscosity which is still relatively low) and focus was on angle orientations, entrance shape, cavitation number, design of nozzle; and for more recent studies, number of holes on the nozzle - termed multi-hole nozzles (Zhong et al., 2014; Sun et al., 2015; Desantes et al., 2016; Zhou et al., 2016; Salvador et al., 2017). Some studies considered the length and diameter of the nozzles as separate factors. However, the importance of geometry and viscosity on $\mathrm{C}_{\mathrm{d}}$ was emphasised and recommended for further studies. Due to the wide range of application of high viscous fluid in various industries and lack of adequate data associated with high viscosity fluid at small Reynolds number. There is an increased need for specific characteristics of the discharge coefficient $\left(C_{d}\right)$ for nozzles at low Reynolds number $(\mathrm{Re})$.

The objectives of the study were: (1) to experimentally study the influence of some flow and geometrical factors on discharge coefficient of high viscous liquid (2) to model the laminar to turbulent flow regime behaviours with fluids of varying viscosities; (3) to develop an empirical model for discharge coefficient for high viscous liquid. 
Table 1: Selected studies on discharge coefficient

\begin{tabular}{|c|c|c|c|c|}
\hline Reference & $\boldsymbol{\beta}$ & $1 / d$ & Re range & Fluids \\
\hline $\begin{array}{l}\text { Lichtarowics et } \\
\text { al., } 1965\end{array}$ & $\begin{array}{l}0.044,0.054 \\
0.071,0.251 \\
0.252\end{array}$ & $\begin{array}{l}0.5,1.0,2.0 \\
4.0,10.0\end{array}$ & $1<\operatorname{Re}>10^{4}$ & $\begin{array}{l}\text { Water, water-glycerin } \\
\text { mixture, oil (viscosity not } \\
\text { given) }\end{array}$ \\
\hline Bohra, 2004 & $0.023<\beta<0.137$ & $0.32<1 / \mathrm{d}<5.72$ & $0.09<\operatorname{Re}<9677$ & $\begin{array}{l}\text { Highly viscous fluid with } \\
\text { non-Newtonian behaviour } \\
\text { (hydraulic fluid) }\end{array}$ \\
\hline $\begin{array}{l}\text { Rahman et al., } \\
2009\end{array}$ & $\begin{array}{l}0.3,0.35,0.47 \\
0.59 \\
0.71\end{array}$ & & $80000-21000$ & \\
\hline $\begin{array}{l}\text { Hollingshead, } \\
2011\end{array}$ & $\begin{array}{l}0.5,0.6 \\
0.65,0.7\end{array}$ & & $\begin{array}{l}1>\operatorname{Re}>500 \\
1000>\operatorname{Re}>5 \times 10^{7}\end{array}$ & $\begin{array}{l}\text { Investigation was done } \\
\text { using different differential } \\
\text { flow meter (Venturi, V- } \\
\text { Cone, Wedge, Standard } \\
\text { concentric orifice plate) at } \\
\text { small Re with the aid of } \\
\text { Computational Fluid } \\
\text { Dynamics (CFD) program } \\
\text { called FLUENT }\end{array}$ \\
\hline
\end{tabular}

\section{Findings}

Experiment showed that when $\mathrm{C}_{\mathrm{d}}$ increased steeply with increase in $1 / \mathrm{d}$ and the rise continued; as $1 / \mathrm{d}$ increases to unity, the $\mathrm{C}_{\mathrm{d}}$ started to fall to the ultimate constant value at $\operatorname{Re}=700$. The fall was rapid, but as $1 / \mathrm{d}$ increased the peak (sharp fall) disappeared although some small but noticeable irregularities could still be found.

An equation relating $\mathrm{C}_{\mathrm{d}}$ to Reynolds number and aspect ratio was proposed. They discovered that this equation fits all but a few points to better than 0.02 in the range of $1 / \mathrm{d}$ from 2 to 10 and $\mathrm{Re}$ from 10 to $2 \times 10^{4}$

An increase in aspect ratio caused an increase in Euler number at small values of Reynolds number

Experiment was conducted at five fixed valve opening positions using five orifice plates respectively. $C_{d}$ positive linear relationship with beta ratio with strong dependence at lower flow rate but for the $\mathrm{Re}$, the relationship was curvilinear except for $\mathrm{Re}$ when the beta ratio was 0.47

As Re increased, $\mathrm{C}_{\mathrm{d}}$ value increased to a maximum before sharply dropping off then remains constant for all increase in Re. The value of $\mathrm{C}_{\mathrm{d}}$ and $\mathrm{Re}$ depended on the shape and other geometrical properties that influenced the nature of the fluid motion 


\section{Ochowiak,}

2013

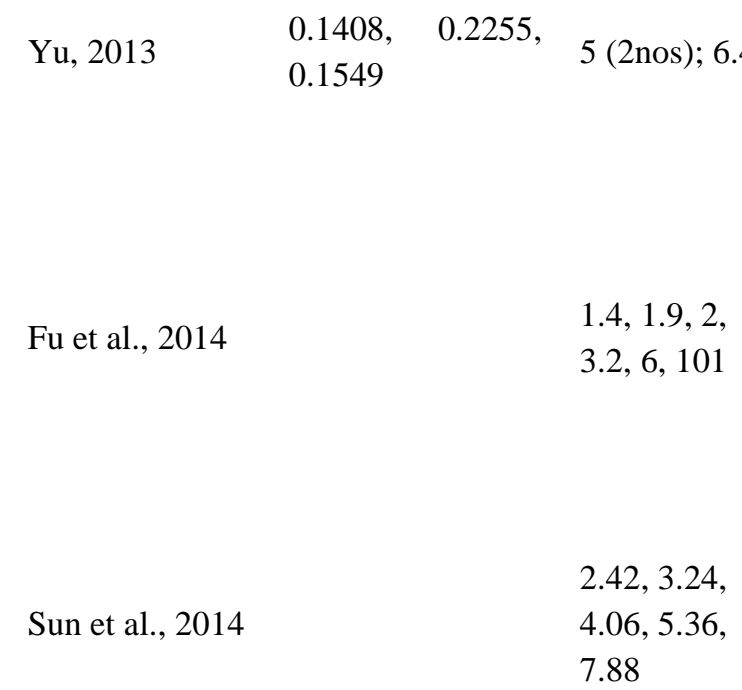

Yin et al., 2014
Ai-glycerol aqueous solutions: Water $(\mu=0.01$ Pa.s) and Glycerol-water $\operatorname{mix}(0.014,0.025,0.037$, $0.08, \quad 0.182$ Pa.s) for

effervescent atomization

Water

Non-Newtonian (gelled propellants)

Diese

$2096-1.2 \times 10^{4}$
The relationship between $C_{d}$ and liquid viscosity for effervescent nozzles, under single and multiphase liquid flow conditions, was investigated as it is said to determine the success or failure of an atomizer. For single phase flow, $\mathrm{C}_{\mathrm{d}}$ increased with increase in $\mathrm{Re}$ value, reached a maximum and became independent of Re beyond a certain point; increase in viscosity reduces flow turbulence resulting in a decrease of $\mathrm{C}_{\mathrm{d}}$, and lastly, $\mathrm{C}_{\mathrm{d}}$ increases with increase in the gas-liquid ratio.

The influence of Re and 1/d were acknowledged, however, at the same pressure difference, back pressure was found to play a role in this effect too. Re regime was subdivided into first critical $\mathrm{Re}$ (cavitation flow) and second critical Re (flip flow). The constant nature of $\mathrm{Cd}$ at high $\mathrm{Re}$ was found to be due to the occurrence of flip flow. Effect of $1 / \mathrm{d}$ was not discussed.

The experiment was conducted to understand the spray characteristics of an impinging-jet injector for gelled propellants fluid and how the orifice geometry affects it. $C_{d}$ increased as $1 / d$ became greater for the different injector exit orifice design studied. Values of $C_{d}$ depended on the shape of the orifice. Additionally, $C_{d}$ decreased when $1 / \mathrm{d}$ become too high.

Studies were on the influence of $1 / d$ and other geometrical factors on flow and cavitation characteristics within a nozzle using numerical simulation. Although this study was not directly related to $C_{d}$, it was observed that it is less significant to study the effect of the nozzle's length without consideration of the orifice's diameter.

Experiment was conducted using venture sonic nozzles with throat diameter $(0.18,0.22,0.28,0.96 \mathrm{~mm})$. Results were discussed at $1 / d=2$, and it was observed that $C_{d}$ increased with increasing throat diameter for a fixed diffuser length; the nozzle length had more impact on $\mathrm{C}_{\mathrm{d}}$ at smaller throat diameter, and $\mathrm{C}_{\mathrm{d}}$ 
Davanlou et al.,

2015

\section{Abdemezzak}

and Huang,

2016

$2,4,6,8$

Desantes et al.,

2016

$1.1 \times 10^{3}-9.7 \times 10^{4}$

Diesel fuel for noncavitating diesel injector nozzles (single- and multi-hole nozzles) $\mathrm{mPa} \mathrm{s}$ ) and water became smaller as the diffusion section increased in length. Other factors studied were diffusion angle and entrance shape.

Glycerol (1.3 and 1.6 Increasing the viscosity decreased $C_{d}$. Variations were small at high Re.

Four different nozzle lengths with same diameter $(1.5 \mathrm{~mm})$ were used to investigate the effect of cavitation on liquid jet atomization characteristics for different $\mathrm{l} / \mathrm{d}$ ratios. Though results of $\mathrm{C}_{\mathrm{d}}$ were plotted against cavitation number, the following observations were made: $C_{d}$ decreased as $1 / d$ increased due to frictional loss, and cavitation number influenced the $\mathrm{C}_{\mathrm{d}}$ more than Re.

Hydraulic characterisation of the injection nozzles were done to determine the variation of $\mathrm{C}_{\mathrm{d}}$ with the $\mathrm{Re}$, specifically. Geometrical data for the study were: $1(773,563,1000 \mu \mathrm{m}-3 \mathrm{nos})$; $\mathrm{d}(126,130,156,138,112 \mu \mathrm{m})$; D $(150,144,195,167,140 \mu \mathrm{m})$. From the research, the relationship between $R e$ and $C_{d}$ exhibited asymptotic behaviour with $\mathrm{C}_{\mathrm{d}}$ increasing as Re increased. This behaviour depended only on the geometry of the nozzle inlet. Theoretical expression developed can be applied to single- and multi-hole nozzles.

The higher the Re, the higher the $C_{d}$. Although the Diesel engine fuel for scope of this work did not cover our geometrical factor multi-hole diesel of interest, it was observed that increasing the injector nozzles inclination decreased not only the $C_{d}$ but also its sensitivity to an increase in Re. 


\section{Experiment Setup and method}

The laboratory test facility was set-up consisting of a glass tank, a down-comer section or nozzle section, flow loop, data acquisition unit and process sensors. Schematic of the test rig is shown in Figure 1. The glass tank was divided into two separate compartments, one for water as working liquid and the second for oil. Each chamber had an inlet point (from the PVC pipes) where the movable nozzle section was attached to enable fluid flow into that section. The nozzle section (Figure 2) consisted of a $1 \frac{1}{22^{\prime \prime}}$ stainless steel pipe with the inlet connected to the inlet point of the sectioned glass tank, and the outlet at the nozzle side, where the test nozzles were attached to the stainless-steel pipe. The flow loop was made up of a closed loop oil and water feed system where test fluids were pumped from storage using Leroy Somer Varmeca $31 \mathrm{~T} 075$ progressive cavity pump (PCP-1, PCP-2) and metered by Endress+Hauser Promag 50 (FA-2) and Promass 83 (FA-1) flow meter, for water and oil respectively, before discharge into the tank via nozzle section and then returned to respective storage tanks. Ball valves (VLV-3 and VLV-4) were used to separate the oil and water line at the Tee joint. The cycle was repeated for different velocities and flow rate during which temperatures, velocity and required parameters values were recorded by the data acquisition unit. The temperature control system consisted of a J-type thermocouple, coils and a Thermo Scientific (HAAKE Pheonix II) refrigerated bath circulator; a GE Druck PMP 1400 was used as the pressure transducers.

The experiment was conducted over flow regimes in the laminar and turbulent region though the focus was in the laminar region. The working fluids used to achieve this were alternatively water and oil. Water was used first to establish benchmark characteristics and to obtain results for less viscous liquids. Next were two oils with viscosities of 350 and $1500 \mathrm{mPa}$.s; both were incompressible and Newtonian. The nozzles used had circular, long orifices and different 
nominal diameters $-10,15$, and $20 \mathrm{~mm}$. These nozzles were characterised by varying lengthto-diameter ratios.

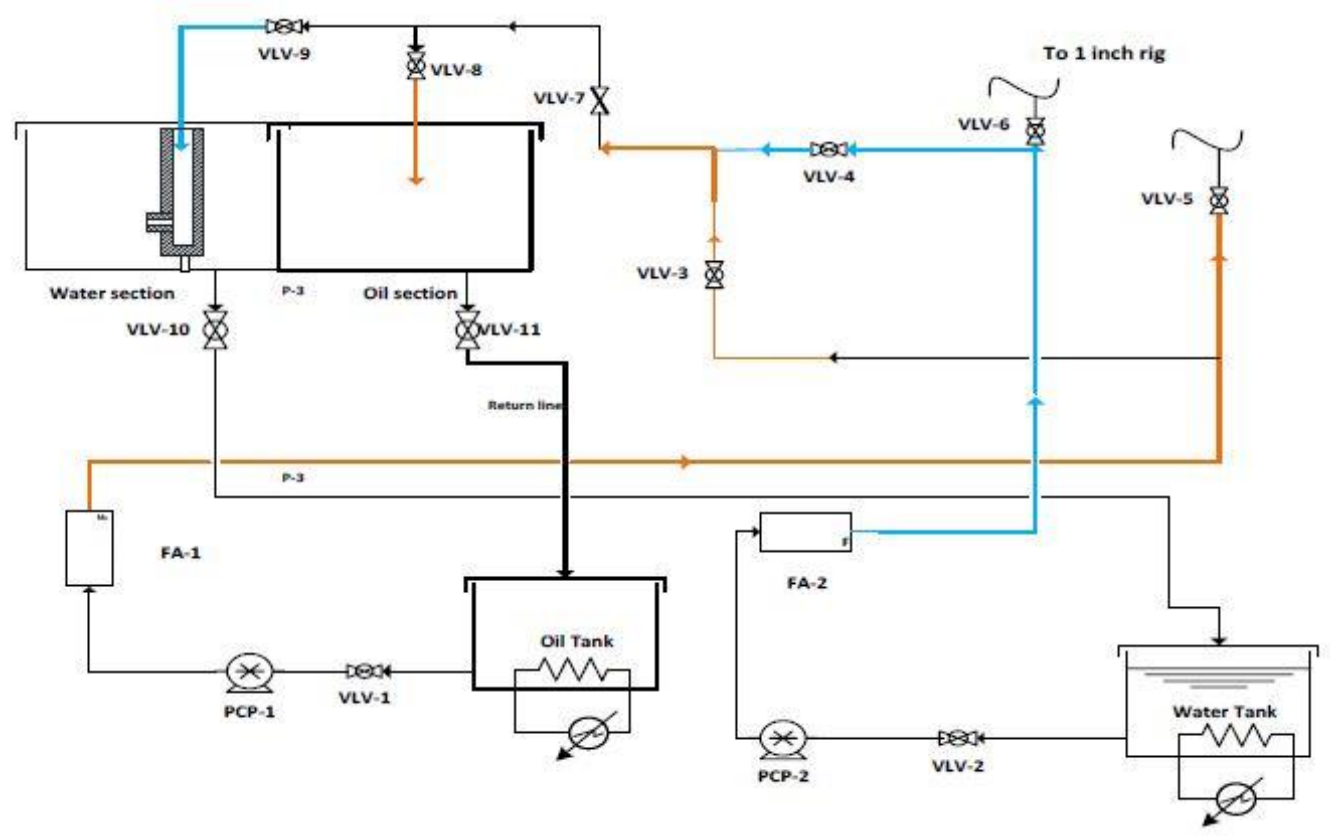

Fig. 1: Schematics of the test rig

The velocity of the discharged fluid (jet velocity) $\left(\mathrm{V}_{\mathrm{j}}\right)$ was determined based on the measured flow rate, density and continuity equation (Eq.2). The jet velocity aided in calculating Reynolds number of the flow which is affected by viscous forces characterising the flow into laminar or turbulent flow regime, and is given as:

$$
V_{j}=V_{p}\left(\frac{D}{d}\right)^{2}
$$

where $\quad V_{j}$ is the jet velocity

$V_{p}$ is the velocity of the fluid in the pipe

$\mathrm{D}$ and $\mathrm{d}$ are the inner diameters of pipe and nozzle respectively.

The pressure loss $(\Delta \mathrm{P})$ across the nozzle, which is the pressure drop that occurred as the fluid was discharged from the pipe through the nozzle to the surrounding environment, varied based on the height of submergence of the nozzle, the surrounding environment (air or fluid), type of 
fluid (water or oil) and losses due to friction. The surrounding environment determined if the outlet pressure was to be taken as just atmospheric pressure or as a piezometric surface to account for pressure head due to liquid level while, losses due to friction were generated by frictional force due to fluid's motion against the surface of the pipe.

Reynolds

number

$$
R e_{j e t}=\frac{\rho V_{j} d}{\mu}
$$

$$
\Delta P=P_{\text {inlet }}-P_{\text {outlet }}
$$

where $\rho$ is the density of the fluid

$\mu$ is the dynamic viscosity of the fluids

$\mathrm{P}_{\text {inlet }}$ is the pressure of flow entering the nozzle

$\mathrm{P}_{\text {outlet }}$ is the pressure of flow exiting the nozzle

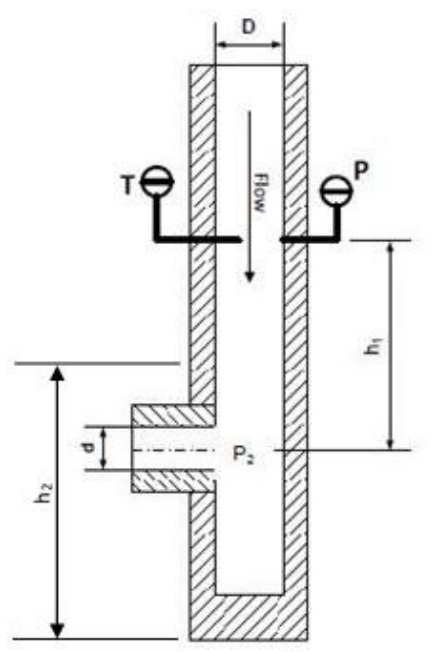

Fig. 2: Schematics of the nozzle section

$$
\begin{gathered}
P_{\text {outlet }}=\rho g h_{2} \\
P_{\text {inlet }}=P_{1}+\rho g h_{1}-\Delta P_{\text {friction }} \\
\Delta P_{\text {friction }}=\frac{f h_{1} \rho V_{p}^{2}}{2 D}
\end{gathered}
$$

where, $\quad \mathrm{h}_{2}$ is the height of submergence 
$\mathrm{h}_{1}$ is the distance between the pressure tapping and centreline of nozzle

$\mathrm{P}_{1}$ is the pressure recorded by the pressure transducer

The discharge coefficient is the product of the flow coefficient of the nozzle and velocity of approach, given as (Lichtarowicz et al., 1965; Jankowski et al., 2008; Ntamba, 2011):

$$
C_{d}=\frac{Q_{v}}{A_{j}} \sqrt{\frac{\rho\left(1-\beta^{4}\right)}{2 \Delta P}}
$$

where,

$$
\begin{aligned}
& C_{d}=\text { Discharge coefficient } \\
& \beta=\text { diameter ratio (ratio of nozzle diameter to pipe diameter) }
\end{aligned}
$$

\section{Results and Discussions}

High viscosity oil and water were used for the experiment to model the laminar and turbulent flow regimes. The experimental results revealed that discharge coefficient varied for Reynolds number, length-to-diameter ratio, and beta ratio of the nozzle. The measurements were conducted for a narrow range of Re hence data covered laminar flow $\operatorname{Re}<100$ and turbulent flow $\operatorname{Re}>1000$. The transition region was not covered due to the specification of available test rig and liquids that were used.

Because of fluid dynamics, which might have affected the method of delivery of the fluids in the flow measurement system, the uncertainty of the test results was estimated. Other possible sources of error may have been from internal data processing, external or process environments like ambient temperature or noise. The statistical method was used, and standard uncertainty values were obtained from the standard deviation of the mean. From calculation, uncertainty 
in measuring the flow rate which was the starting point of data calculation were 0.0013 for turbulent range and 0.435 for the laminar flow regime.

\subsection{Effect of viscosity on $\mathrm{C}_{d}$}

The influence of viscosity on $C_{d}$ is presented in fig. 3-4. From our results, increasing viscosity led to a decrease in $\mathrm{C}_{\mathrm{d}}$ for the range of nozzle diameter studied. The maximum value of discharge coefficient obtained for the flow was lower for highly viscous fluid than one achieved by the less viscous fluid. This behaviour was also observed by Osipowicz (2014), fig. 4 when he carried out a similar experiment but at a broader viscosity range. The region of low $\mathrm{Re}$ values, also called laminar region, are typically dominated by highly viscous liquids. Therefore, the impact of viscosity on $\mathrm{C}_{\mathrm{d}}$ was significant in this region because the vena contracta effect was smaller due to the high internal friction of the test fluid. This means that at low $\operatorname{Re}, \mathrm{C}_{\mathrm{d}}$ was lower because the discharge velocity was limited mainly by the friction phenomena. The formation of central air core in the liquid jet was inhibited making the liquid exit as a full jet. Ochowiak (2013) and Davanlou et al. (2015) also noted similar observation.
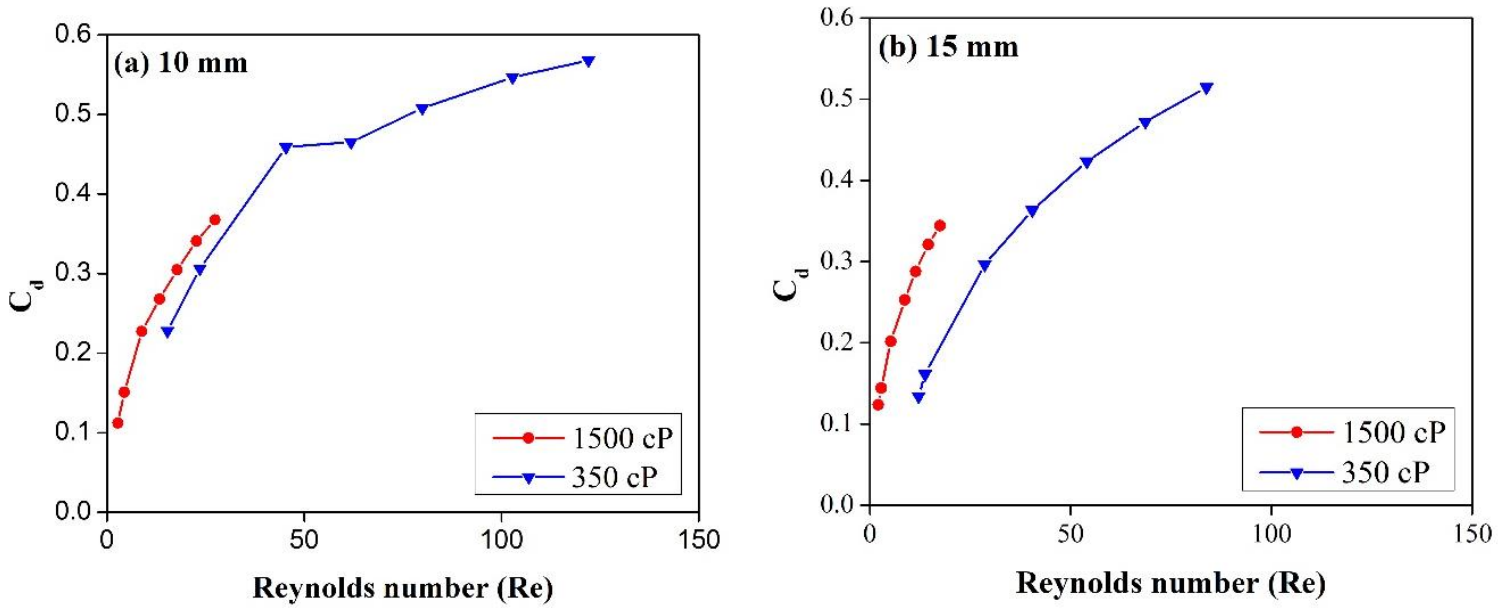

Fig. 3: Effect of viscosity on $C_{d}$ in (a) $10 \mathrm{~mm}$ and (b) $15 \mathrm{~mm}$ nozzle bore size. 


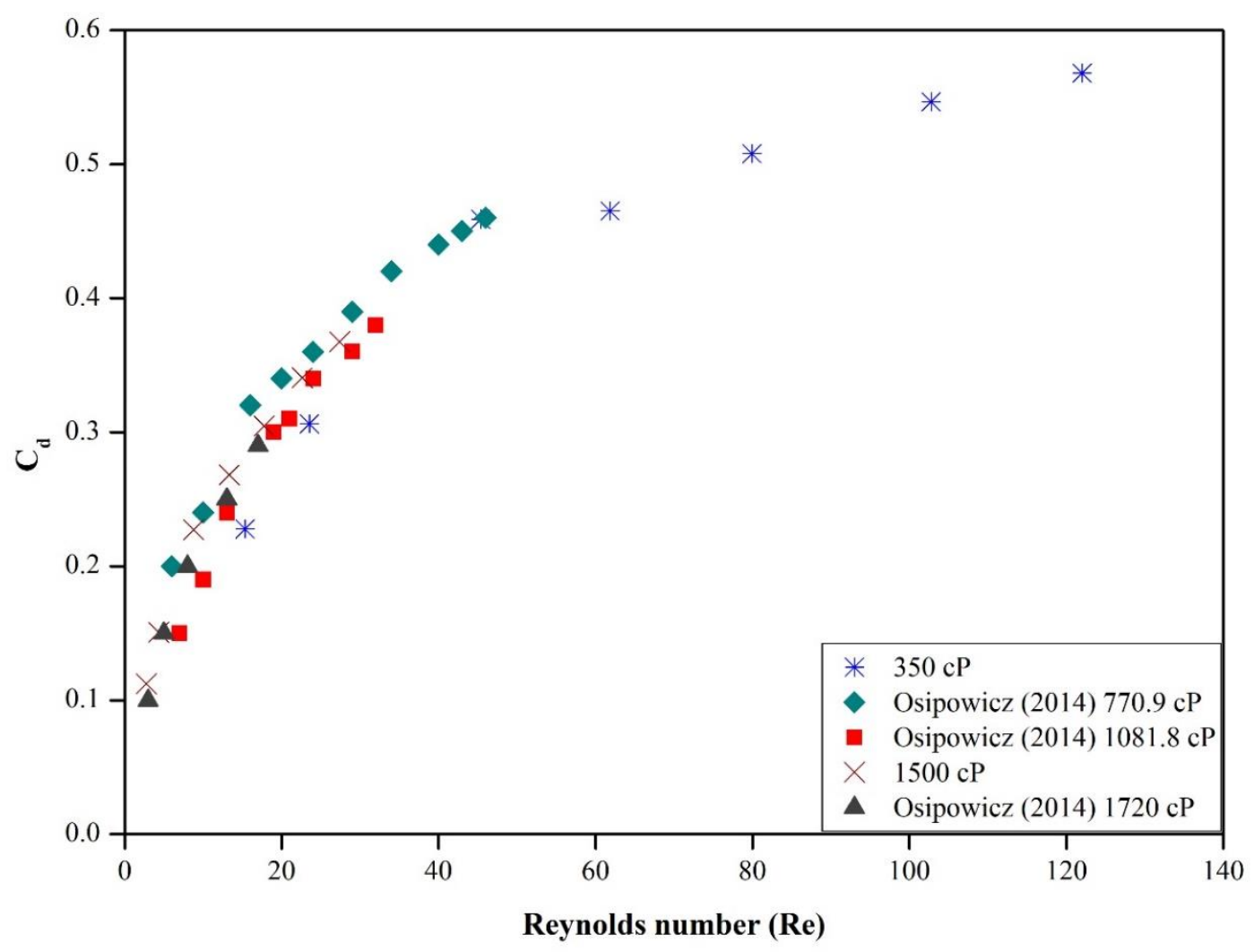

Fig. 4: Effect of viscosity at 10mm nozzle bore size including data from previous studies.

The effect of viscosity reduced as the flow rate increased (increasing $\mathrm{Re}$ ) and $\mathrm{C}_{\mathrm{d}}$ attained a relatively constant value which was independent of any increase in viscosity (fig. 5c). This behaviour occurred because the dissipation energy due to viscosity became less significant in the turbulent region (Kiljanski '93). The constant $C_{d}$ value is mainly decided by nozzle geometries and other design characteristics.

\subsection{Effect of Geometrical Factors on $\mathbf{C}_{d}$}

Most geometrical factors investigated in recent studies are related to nozzle length, throat diameter, angle orientation, number of holes or orifices, shape of the nozzles and others (Ghassemieh et al., 2006; Aori 2015; Alam et al., 2016; Desantes et al., 2016; Salvador et al., 2017). This study focused on $1 / d$ and $\beta$ ratio. The data obtained showed that $C_{d}$ increased with increase in 1/d ratio (Fig 5). Similar trends were observed in another experiment conducted on 
the same test facility but with additional nozzle sizes (Osipowicz, 2014). $C_{d}$ was lower for smaller length-to-diameter ratio because the vena contracta formed by the liquid jet had no time to re-expand in the short nozzle. Increasing the length-to-diameter ratio enabled the jet expansion in the flow passage resulting in an increasing $C_{d}$. Lichtarowicz et al., (1965) work indicated that the highest ultimate value of $\mathrm{C}_{\mathrm{d}}$ with this design is about 0.81 and corresponds to an aspect ratio of 2.0. Data from this experiment showed a $10 \%$ increase from this value.
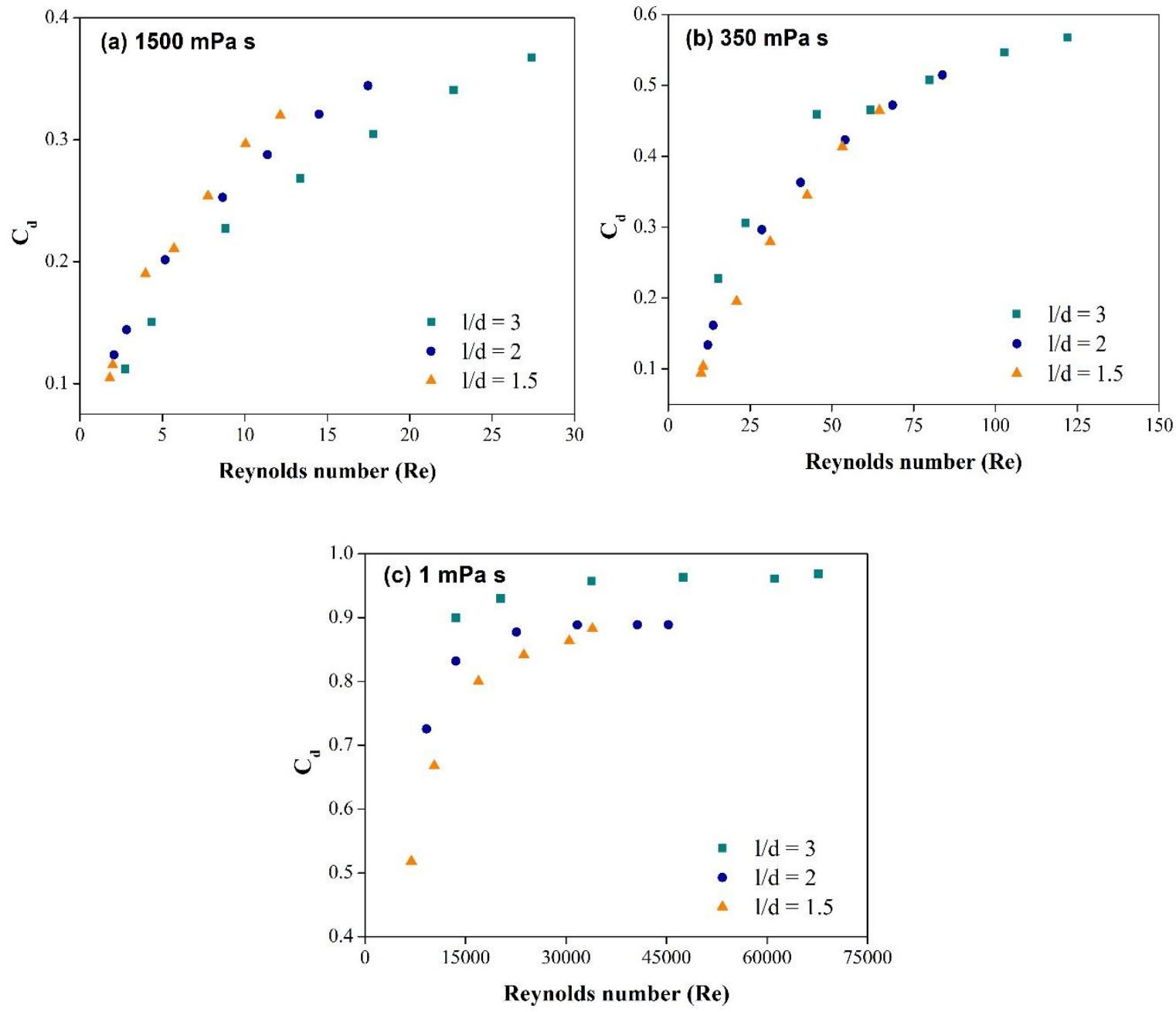

Fig. 5: Variation of discharge coefficient with Re at different $1 / d$ for fluid viscosity (a) 1500 mPa s (b) $350 \mathrm{mPa} \mathrm{s}$, (c) $1 \mathrm{mPa}$. 
It is pertinent to note that the significance of length-to-diameter ratio is dependent on the length of the nozzle which must be long enough for the flow downstream of the entry plan to be affected by the presence of a nozzle bore. Impact of nozzle length is higher at smaller nozzle diameter (Yin et al., 2014). Like Fu et al., (2014), as the length-to-diameter ratio is increased it gets to a point where additional frictional pressure loss causes the $C_{d}$ to decrease. The effect of length-to-diameter ratio decreases at high Reynolds number, and $\mathrm{C}_{\mathrm{d}}$ becomes diameter ratio dependent.

Another important factor is the beta ratio. First because, for a fixed pipe diameter, the flow area becomes larger as nozzle bore size increases resulting in corresponding high $\beta$-ratio values. $C_{d}$ measures how much of the flow area is used by the liquid flowing through the final discharge orifice, in this case, the nozzle; therefore, increasing the nozzle bore size resulted in a reduction of flow area used during discharge of fluid through the nozzle, for a fixed flow rate. Secondly, at small flow rates, the pressure drop across the nozzle was smaller for higher $\beta$ ratio compared to smaller $\beta$ ratio, but as flow rate increases, nozzles with higher $\beta$ ratio developed greater frictional losses compared to nozzles with a smaller $\beta$ ratio, thereby decreasing the discharge coefficient. However, for $\beta=0.263$, its influence on $C_{d}$ was insignificant. A similar observation was noted by Lichtarowicz et al., (1965) who also stated that the impact of d/D is unlikely to exceed 1 per cent at any Reynolds number.

\subsection{Empirical Correlation}

One of the objectives of this research work was to develop a correlation that can be used to predict the discharge coefficient for high viscous fluid through nozzles. Existing models and correlations are not well suited for predicting this parameter for high viscous flow. An attempt was made to fill this gap in knowledge. Multiple linear regression method was used to analyse 
the experimental results using the SigmaPlot software, version 12. The data was first analysed over the range of laminar to a turbulent regime and a correlation obtained. The r-squared value of this correlation was very low because of the lack of data over the transition period and as such the software would have had to do much estimation. The response of the dependent variable to changes in the independent variable was not linear at all points and as such the reliability of the correlation obtained would be affected.

Consequently, the method was changed to nonlinear regression and was carried out on the laminar region alone. Data from this study and previous studies (Lichtarowicz et al., 1965; Hulf and Hogh, 1967; Osipowicz, 2014) were used to develop a model for predicting $\mathrm{C}_{\mathrm{d}}$ as a function of $\mathrm{Re}$ and $1 / \mathrm{d}$, as shown in Eq. (8). The proposed model has a correlation coefficient $\left(\mathrm{R}^{2}\right)$ of 0.9541 and a standard error of estimate of 0.0624 . It is valid for nozzle diameters $10-20 \mathrm{~mm}$ and Reynolds number up to 200. Care should be taken in the use of this correlation outside this range.

$$
\mathrm{C}_{\mathrm{d}}=0.1901-803.7662\left(1-\mathrm{e}^{-0.00002429 l / d}\right)+0.7094\left(1-\mathrm{e}^{-0139 R e}\right)
$$

Eq. 8 was used to predict $C_{d}$ at different Reynolds number, and $1 / d$ ratio explored within our work, and the mean standard deviation between the predicted and experimental data was 0.0231. The actual $\mathrm{C}_{\mathrm{d}}$ results were compared with the values predicted by the model, Fig. 6 . At $\mathrm{C}_{\mathrm{d}}$ between 0.1 and 0.5 , predicted $\mathrm{C}_{\mathrm{d}}$ was approximately linear to the experimental $\mathrm{C}_{\mathrm{d}}$ with an average standard deviation of 0.0191 . This region was characterised by smaller nozzle diameters and low Re number (up to 120). A few over predictions occurred between 0.55 and 0.7 because there were not enough experimental data to use. This slight error, which reduced to r-squared from 1.000 to 0.9541 , was adjusted from $\mathrm{C}_{\mathrm{d}}$ above 0.8 . 


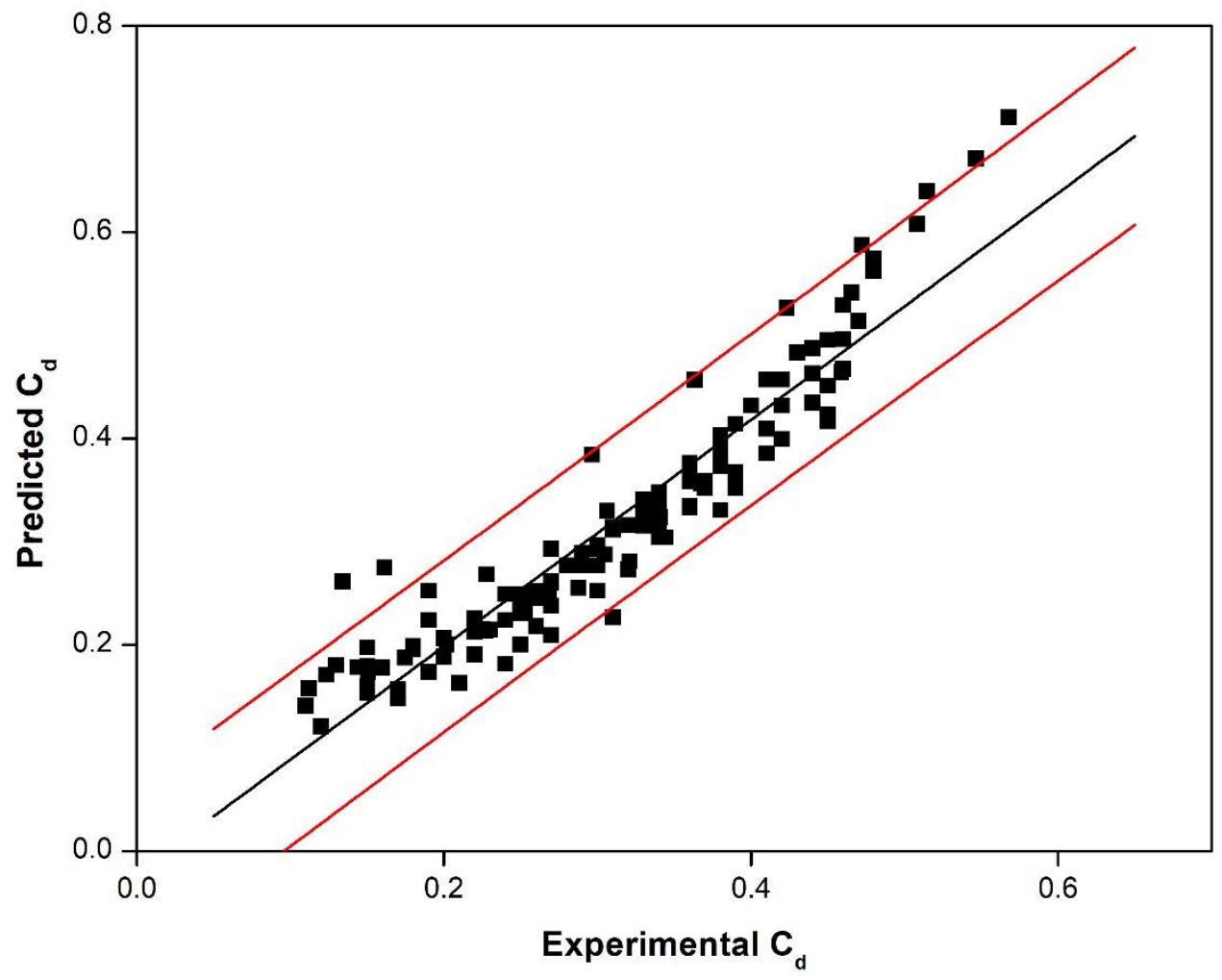

Fig. 6: Predicted $C_{d}$ versus Experimental $C_{d}$

\subsection{Comparing results with past work done by other researchers.}

The lack of a quantitative theory which applies for high viscous flow led to empirical correlation to be developed using results from this experiment. There are not many correlations established for high viscous flows. However, the correlations developed in this study were compared, at the length-to-diameter ratio of 2, with existing correlations developed by other researchers as is shown in Fig. 9.

Asihman (1961) proposed

$$
\frac{1}{C_{d}}=1.23+\frac{58 l / d}{R e}
$$

for $R e$ between 100 and $1.5 \times 10^{5}$ and $l / d$ in the range of $2-5$ with an accuracy of $1.5 \%$. Lichtarowicz et al. (1965) observed that as $R e$ tend to infinity, the $\mathrm{C}_{\mathrm{d}}$ was 0.813 irrespective 
of the variation in $l / \mathrm{d}$ and so proposed some modification (Eq. 10) to the equation (Eq. 9) to accommodate variation of $\mathrm{C}_{\mathrm{d}}$ with $l / d$ at high $\mathrm{Re}$.

$$
\frac{1}{C_{d}}=\frac{1}{C_{d u}}+\frac{20}{R e_{h}}\left(1+\frac{2.25 l}{d}\right)-\frac{0.05\left(\frac{l}{d}\right)}{1+7.5\left(\log 0.0015 R e_{h}\right)^{2}}
$$

This equation was found to be fit for all but a few for $l / d$ ratio in the range of 2 to 10 and $R e$ from 10 to $2 \times 10^{4}$. Another correlation was suggested by Nakayama (1961) who from his results proposed Eq. 11 for $l / d$ in the range of 1.5 to 17 and $R e$ in the range 550 to 7000 .

$$
C_{d}=\frac{R e^{5 / 6}}{17.11 l / d+1.65 R e^{0.8}}
$$

He claimed accuracy of $2.8 \%$ for Eq. 11. Osipowicz (2014) also proposed a universal formula for determining $C_{d}$ as given in Eq. 12 for Re in the range of 0 to 100 . He claimed accuracy of $3.99 \%$.

$$
C_{d}=0.1402 R e^{0.3427}-0.0239 l / d
$$

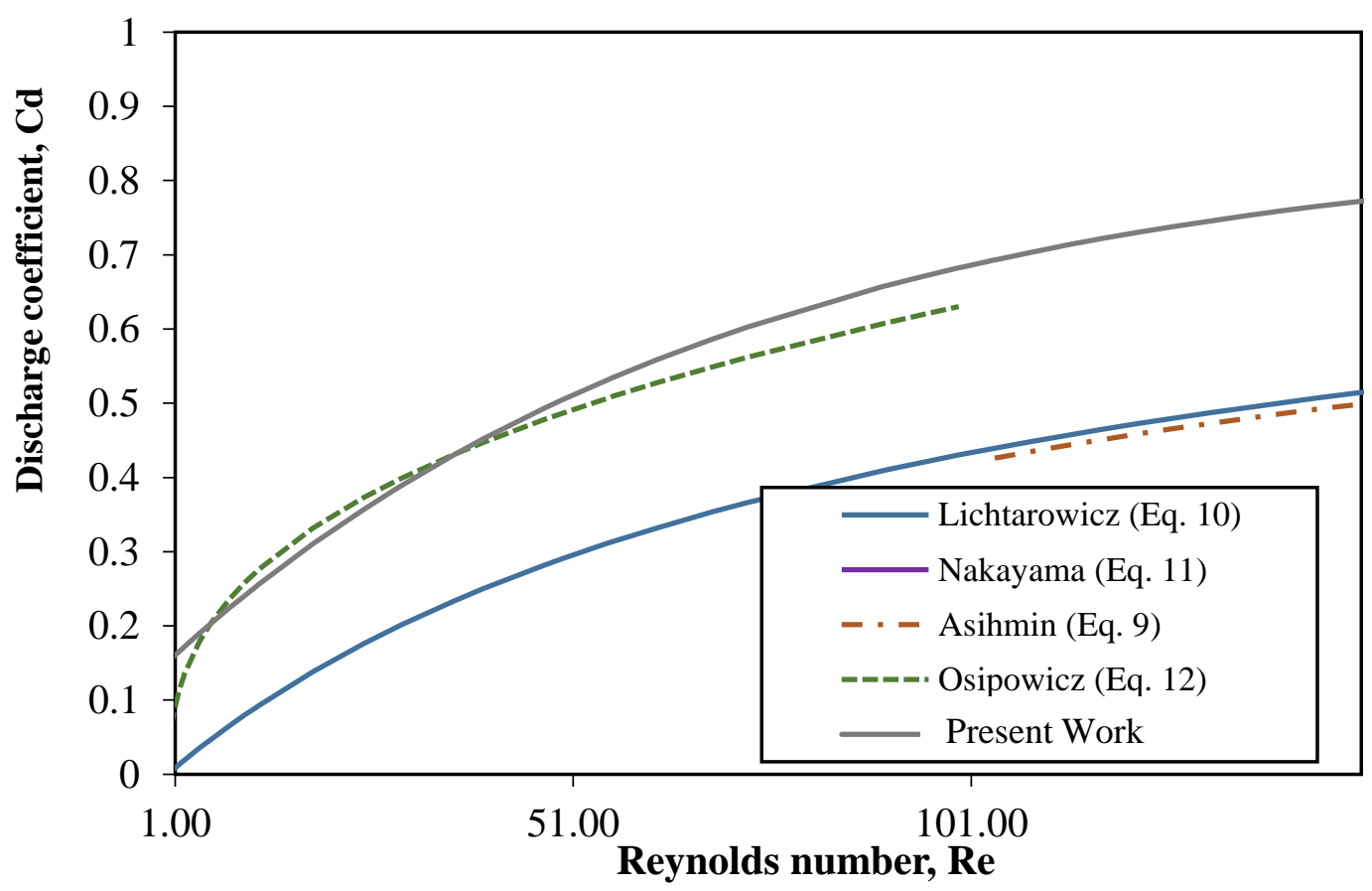

Fig 7 Comparison of various empirical correlation at $1 / \mathrm{d}=2$ 


\section{Conclusions}

Experimental study shows that Reynolds number, beta ratio and length-to-diameter ratio have marked effects on $\mathrm{C}_{\mathrm{d}}$ where the former has curvilinear relationship and latter has a positive linear relationship. For this reason, there will have an optimum value of beta ratio for maximum $C_{d}$. The impact of these factors is very significant at low flow rates where viscosity plays a major role; the influence of viscosity diminishes as the flow rate increases and this, in turn, lessens the influence of Reynolds number and $1 / \mathrm{d}$, leaving $\mathrm{C}_{\mathrm{d}}$ to be primarily dependent on the geometrical properties. Pressure loss across the nozzle was another important parameter observed in the study. It was notably dependent on the geometry of the nozzle, flow rate and viscosity of the fluid. In conclusion, the following observations were made:

1. The value of maximum $\mathrm{C}_{\mathrm{d}}$, at same discharge rate, varied for each nozzle sizes because of factors like nozzle diameter, which is relative to the flow area used.

2. The effect of viscosity was significant at low viscosity and reduced as viscosity reduced.

3. $C_{d}$ increased with increasing value of $1 / d$ ratio. It is important to note that the length of the nozzle was kept constant throughout the experiment. Increasing the beta ratio led to a decrease in $C_{d}$.

This research work confirms the conclusions of past research. Although, due to restrictions from the design of available test rig and fluid used for the experiment, behaviour within the transition region could not be observed. This can form a basis for further research, to study the influence of Reynolds number, beta ratio and length-to-diameter ratio on the discharge coefficient of a nozzle in the transition phase.

\section{Acknowledgement}

The authors will like to acknowledge the contributions of Flumix Limited UK and Santander Bank for sponsoring this research work. S. Essien is also grateful to Prof O. Essien, her life- 
time supervisor, for his encouragement and technical review of this article. The authors thank Mr Daniel Onwude for his technical inputs and support towards developing the correlation. 


\section{References}

1. Abderrezzak, B., and Huang, Y. (2017). Investigation of the Effect of Cavitation in Nozzles With Different Length to Diameter Ratios on Atomization of a Liquid Jet. Journal of Thermal Science and Engineering Applications, 9(3), 31011-31014. Retrieved from http://dx.doi.org/10.1115/1.4036438

2. Alam, M. M. A., Setoguchi, T., Matsuo, S., and Kim, H. D. (2016). Nozzle geometry variations on the discharge coefficient. Propulsion and Power Research, 5(1), 22-33. https://doi.org/10.1016/j.jppr.2016.01.002

3. Aori, G., Hung, D., Zhang, M., Zhang, G., \& Li, T. (2016). Effect of Nozzle Configuration on Macroscopic Spray Characteristics of Multi-Hole Fuel Injectors under Superheated Conditions. Atomization and Sprays, 26(5), 439-462. https://doi.org/10.1615/AtomizSpr.2015011990

4. ASME. (1971). Fluid Meters: Their Theory and Application (6th Edition). ISBN 9780791806432.

5. Bohra, LK (2004), Flow and pressure drop of highly viscous fluids in small aperture orifices. Dissertation, Georgia Institute of Technology

6. Davanlou, A., Lee, J. D., Basu, S., \& Kumar, R. (2015). Effect of viscosity and surface tension on breakup and coalescence of bicomponent sprays. Chemical Engineering Science, 131, 243-255. https://doi.org/10.1016/j.ces.2015.03.057

7. Desantes, J. M., López, J. J., Carreres, M., and López-Pintor, D. (2016). Characterization and prediction of the discharge coefficient of non-cavitating diesel injection nozzles. Fuel, 184, 371-381. https://doi.org/10.1016/j.fuel.2016.07.026

8. Fu, Q., Yang, L., Cui, K., and Zhuang, F. (2014). Effects of Orifice Geometry on Gelled Propellants Sprayed from Impinging-Jet Injectors. Journal of Propulsion and Power, 30(4), 1113-1117. https://doi.org/10.2514/1.B35144 
9. Ghassemieh, E., Versteeg, H. K., \& Acar, M. (2006). The effect of nozzle geometry on the flow characteristics of small water jets. Proceedings of the Institution of Mechanical Engineers, Part C: Journal of Mechanical Engineering Science, 220(12), 1739-1753. https://doi.org/10.1243/0954406JMES430

10. Hobbs, JM and Humphreys, JS (1990), "The effect of orifice plate geometry upon discharge coefficient”, Flow Meas. Instrum. Vol. 1, p.133-140

11. Hollingshead, CL (2011), Discharge coefficient performance of venturi, standard concentric orifice plate, V-cone and wedge flow meters at small Reynolds numbers. All Graduate Theses and Dissertations. Paper 869

12. Hulf, HJ and Hogh, MS (1967) "Flow measurements with orifices and nozzles at the low Reynolds numbers encountered in process pilot plants" Development in Instrumentation and Control of Laboratory and Pilot Plant Process Equipment. World Petroleum Congress.

13.Husain, ZD (2010), Theoretical uncertainty of orifice flow measurement, http://www2.emersonprocess.com/siteadmincenter/PM\%20Daniel\%20Documents/Th eoretical-Uncertainty-of-Orifice-Flow-Measurement-techWpaper.pdf

14. Jankowski, TA, Schmierer, EN, Prenger, FC, and Ashworth. SP (2008), “A Series Pressure Drop Representation for Flow through Orifice Tubes”, J. Fluids Eng., Vol. 130, No. 5, p. 051204-051204-7. doi:10.1115/1.2907408

15. Lichtarowicz, A, Duggins, RK and Marklan, E (1965), "Discharge coefficients for incompressible non-cavitating flow through long orifices", Journal Mechanical Engineering Science, vol. 7, no. 2, pp. 210.

16. Metron Corporation (1976), "Fluid flow measurement", in Physical Measurement, NAVAIR 17-35QAL-2 ed, U. S. Navy, California, pp. 1-56. 
17. Neutrium (2015), Discharge coefficient for nozzles and orifices. http://neutrium.net/fluid_flow/discharge-coefficient-for-nozzles-and-orifices/ Assessed on 23-Feb 2016

18. Ntamba, BMN (2011), Non-Newtonian pressure loss and discharge coefficients for short square-edged orifice plates. Dissertation, Cape Peninsula University of Technology

19. Ochowiak, M. (2013). The experimental study on the viscosity effect on the discharge coefficient for effervescent atomizers. Experimental Thermal and Fluid Science, 50, 187-192. https://doi.org/10.1016/j.expthermflusci.2013.06.008

20. Prohaska, P. D., (2008), Investigation of the discharge coefficient for circular orifices in riser pipes. Dissertation, Clemson University

21. Rahman, M. M., Biswan, R., and Mahfuz, W. I., (2009), "Effects of beta ratio and Reynolds number on $\mathrm{C}_{\mathrm{D}}$ of orifice meter", Journal of Agriculture and Rural $\begin{array}{llllll}\text { Development, } & \text { Vol. } & 7, & \text { No. } & 1 \& 2, & \text { p. }\end{array}$ http://www.banglajol.info/index.php/JARD/article/download/4436/3652

22. Salvador, F. J., Lopez, J. J., De la Morena, J., and Crialesi-Esposito, M. (2017). Experimental investigation of the effect of orifices inclination angle in multihole diesel injector nozzles. Part $1-$ Hydraulic performance. Fuel. https://doi.org/10.1016/j.fuel.2017.04.019

23. Sun, Z.-Y., Li, G.-X., Chen, C., Yu, Y.-S., and Gao, G.-X. (2015). Numerical investigation on effects of nozzle's geometric parameters on the flow and the cavitation characteristics within injector's nozzle for a high-pressure common-rail DI diesel engine. Energy Conversion and Management, 89, 843-861. https://doi.org/10.1016/j.enconman.2014.10.047

24. Yin, Z.-Q., Li, D.-S., Meng, J.-L., and Lou, M. (2014). Discharge coefficient of small 
sonic nozzles. Thermal $\quad$ Science, 18(5), 1505-1510. https://doi.org/10.2298/TSCI1405505Y

25. Yu, B., Fu, P.-F., Zhang, T., and Zhou, H.-C. (2013). The influence of back pressure on the flow discharge coefficients of plain orifice nozzle. International Journal of Heat and Fluid Flow, 44, 509-514. https://doi.org/10.1016/j.ijheatfluidflow.2013.08.005

26. Zhong, W., He, Z., Wang, Q., Shao, Z., and Tao, X. (2014). Experimental study of flow regime characteristics in diesel multi-hole nozzles with different structures and enlarged scales. International Communications in Heat and Mass Transfer, 59, 1-10. https://doi.org/10.1016/j.icheatmasstransfer.2014.10.001

27. Zhou, L.-Y., Dong, S.-F., Cui, H.-F., Wu, X.-W., Xue, F.-Y., and Luo, F.-Q. (2016). Measurements and analyses on the transient discharge coefficient of each nozzle hole of multi-hole diesel injector. Sensors and Actuators A: Physical, 244, 198-205. https://doi.org/10.1016/j.sna.2016.04.017 